Document downloaded from:

http://hdl.handle.net/10251/104730

This paper must be cited as:

Torregrosa-Jaime, B.; Corberán, JM.; Payá-Herrero, J.; Delamarche, JL. (2017). Thermal characterisation of compact heat exchangers for air heating and cooling in electric vehicles. Applied Thermal Engineering. 115:774-781. doi:10.1016/j.applthermaleng.2017.01.017

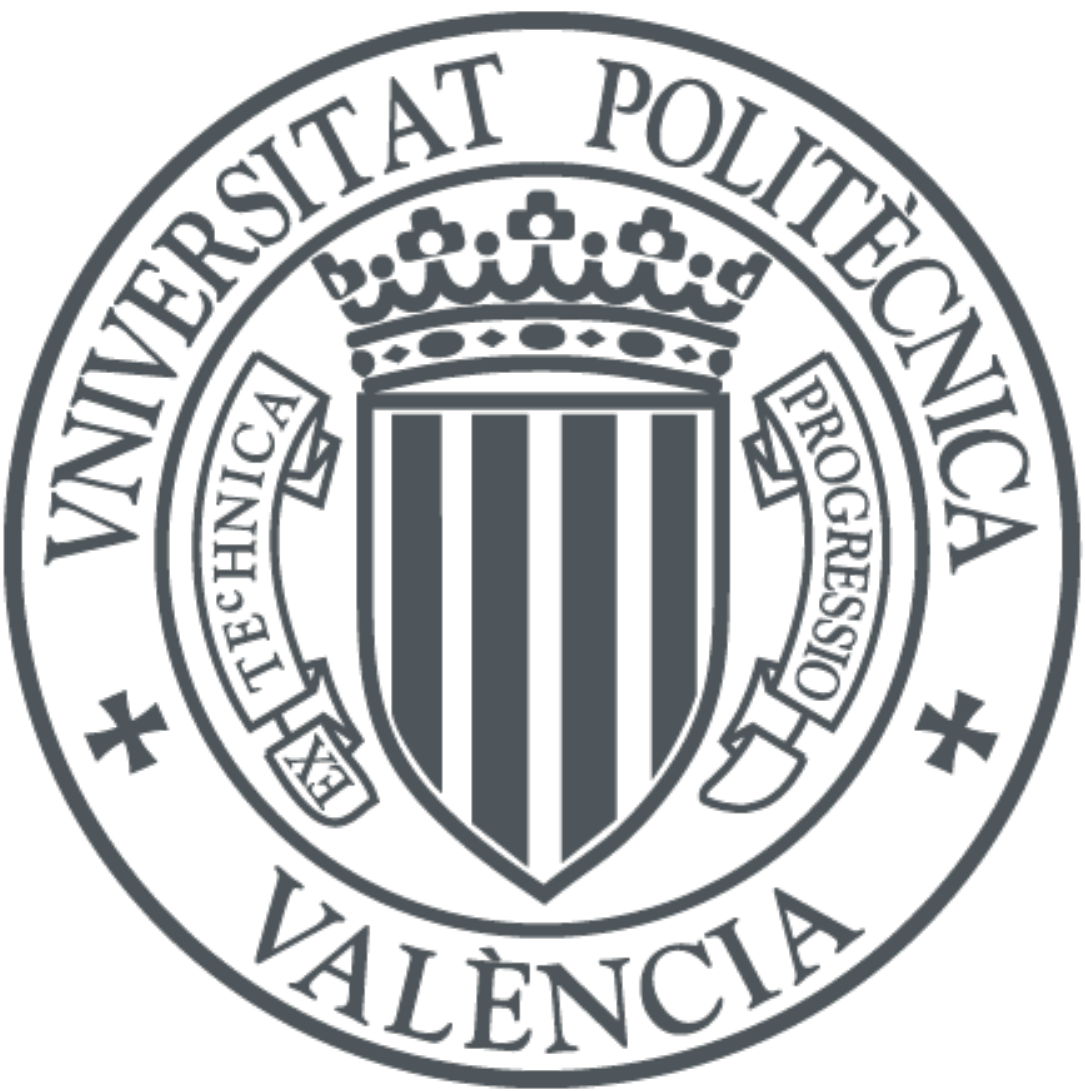

The final publication is available at

http://dx.doi.org/10.1016/j.applthermaleng.2017.01.017

Copyright Elsevier

Additional Information 


\title{
THERMAL CHARACTERISATION OF COMPACT HEAT EXCHANGERS FOR AIR HEATING AND COOLING IN ELECTRIC VEHICLES
}

\author{
B. Torregrosa-Jaime ${ }^{1, *}$, J.M. Corberán ${ }^{1}$, J. Payá ${ }^{1}$, J.L. Delamarche² \\ ${ }^{1}$ IUIIE, Universitat Politècnica de València, Camino de Vera s/n, ed. 8E cubo F 5 ${ }^{\circ}, 46022$ Valencia, Spain \\ ${ }^{2}$ MAHLE Behr France Rouffach S.A.S, 5 Avenue de la Gare, 68250 Rouffach, France
}

\begin{abstract}
The use of air conditioning in all-electric cars reduces their driving range by $33 \%$ in average. With the purpose of reducing the energy consumption of the vehicle and optimising the performance of the batteries, the mobile airconditioning can be integrated with the temperature control system of the powertrain by means of a coolant loop. In such layouts, the air-to-coolant heat exchangers must operate efficiently in both air heating and cooling modes. Dynamic simulation tools comprising the entire thermal system are essential to assess its performance. In this context, fast but accurate models of the system components are required.

This paper presents the thermal characterization of a commercial compact louvered-fin flat-tube heat exchanger (heater core) for this novel application, based on an experimental campaign comprising 279 working points that reflect real air-conditioning (heating and cooling) working conditions. A general methodology to fit a single correlation of the global heat transfer coefficient for both dry and wet working conditions is explained. The semiempirical correlation developed is employed in a single-node model of the heat exchanger that requires minimal computation time. The present model predicts the heat transfer rate with an average deviation of $3.5 \%$ in the cases with dehumidification and $1.9 \%$ in the cases when the heat exchanger remains dry.
\end{abstract}

KEYWORDS: Heat exchanger, Louvered fin, Correlation, Wet condition, Modeling, Automotive

\footnotetext{
* Corresponding author. B. Torregrosa-Jaime, E-mail: bartorja@iie.upv.es, Tel: +34 963879122
} 


\section{INTRODUCTION}

The use of the air-conditioning (AC) in electric cars decreases the driving range by $33 \%$ considering an average use (Lee et al., 2013). Compared to conventional cars, all-electric cars face an additional challenge: the waste heat from the powertrain of all-electric vehicles is not enough to provide a comfortable environment in winter. Electric heaters have been traditionally employed for warming the air inside the cabin, leading in winter to a reduction in the autonomy of the vehicle up to the 50\% (Leighton, 2015). In order to shorten the energy consumption due to the AC and hence extend their autonomy, the most recent commercial all-electric cars already include reversible heat pumps (RHP).

A step further in this direction is to integrate the thermal management system of the powertrain with the cabin AC system. This concept enables not only to recover the waste heat from the electric components, namely the power electronics, the electric motor and the batteries, but also to control their temperature in order to achieve an optimum performance. Several architectures that integrate the electric vehicle thermal systems have been proposed and tested (Qi, 2014). A convenient solution is to employ a coolant loop to communicate the different components with the cabin and the ambient air, as proposed for instance by Leighton (2015), Kowsky et al. (2012) or Zhou (2008). In such layouts, reducing the length of the lines and the number of heat exchangers is essential to minimise weight, volume and thermal losses. Therefore, the air-to-coolant heat exchangers must operate efficiently in both heating and cooling modes, under dry and wet conditions.

Compact louver-fin flat-tube heat exchangers (HEXs) are widely employed in automotive applications, consequently there are numerous studies about their performance especially under dry conditions, as reviewed by Park and Jacobi (2009a, 2009b). Finding general laws for compact HEXs is difficult given their complex fin geometries. Park and Jacobi (2009b) provided a comprehensive characterisation of the thermo-hydraulic performance of the air-side of compact HEXs under dry and fully wet conditions. They developed Colburn $\mathrm{j}$ - and friction factor correlations to predict the louver-fin flat-tube HEX performance as a function of its geometry, however their accuracy is limited by the complexity of the phenomena and the large number of parameters to be considered. Partially wet conditions are avoided in that study, nevertheless they are usual in air cooling applications. More recently, Jokar et al. (2010) presented a test facility consisting of an automotive RHP with secondary coolant loops in which five different air-to-coolant compact HEXs were tested. The discussion of the results focuses on the coolant side and the effect of condensation on the air side is not analysed. Vaisi et al. (2011) studied two types of louvered fins configurations in an automotive radiator, but the temperature working conditions differ significantly from those of the air-conditioning applications. Xu et al. (2015) compared the performance of compact HEXs with wavy and louvered fins under wet and frosting conditions working as evaporators. Automotive condensers and evaporators were also measured and compared by Liang et al. (2015) under dry and wet conditions. In their study, Liang et al. (2015) assessed about the suitability of the existing correlations for the prediction of the air-side heat transfer performance of these HEXs by means of a multi-node model.

In vehicle applications, simulation tools comprising the entire AC system are essential to assess its performance under a wide range of dynamic working conditions. All the loops and the electrical auxiliaries shall be included in the models in order to find the synergies among the components (Bjurling et al., 2014). Grey box models offer a compromise between generalisation capabilities, accuracy and simulation time (Afram and JanabiSharifi, 2014). In this context, single-node or lumped parameter models of the HEXs are more convenient than multi-node or distributed parameter models due to its simplicity and speed. However, the traditional effectiveness approach is not accurate when the HEX works under dynamic dry and wet conditions, in which the boundary between the dry and wet surfaces moves. Several authors have developed simple dynamic HEX models for cooling coils with dehumidification (Braun et al., 1989; Jin et al., 2006; Oliet et al., 2007). Among them, the approach by Braun et al. (1989) has demonstrated a good accuracy with minimal modelling effort and computation time.

In this paper, the thermal characterisation of a commercial compact louver-fin flat-tube HEX under dry and wet conditions is presented. The measured air-to-coolant HEX is intended for a novel application in both heating and cooling of an electric minibus cabin. With this purpose, a comprehensive experimental campaign has been carried out as a part of the European ICE Project FP7 (2014). Rather than analysing the performance of the selected geometry as previous studies did, the present work focuses on the operating conditions of the HEX. As a novelty, partially wet working conditions that are usual in air-conditioning applications are intentionally included and analysed. From these results, a methodology to fit a single everywhere correlation of the global heat transfer coefficient of the compact HEX for both working modes is explained. The developed correlation can be employed to build a semiempirical HEX model that considers dehumidification, based on the approach by Braun et al. (1989). The present model has provided excellent validation results and is useful for its integration a dynamic model of the entire mobile AC system (Torregrosa-Jaime et al., 2013a). 


\section{EXPERIMENTAL METHOD}

In the European ICE Project FP7 (2014), an innovative air-conditioning system for an electric minibus was developed. Specifically, the project addressed the design of a magnetocaloric heat pump that was intended for replacing the vapour-compression heat pump in a water-to-water layout. For compatibility reasons, the rest of the components of the air-conditioning system were kept the same regardless of the heat pumping technology employed (Torregrosa-Jaime et al., 2013b). Fig.1 shows a scheme of the designed system, which included the water-to-water heat pump (HP), the power electronics of the vehicle (PE) and two intermediate coolant loops in which the air-to-coolant HEXs had to work in both cooling and heating modes. Three units of the commercial compact HEX A51-KS423 by the ICE Project partner MAHLE Behr (Figs. 2 and 3 and Table 1) were chosen for the coolant loop to the minibus cabin. This model is a louvered-fin flat-tube aluminium heat exchanger is used more commonly as heater core.
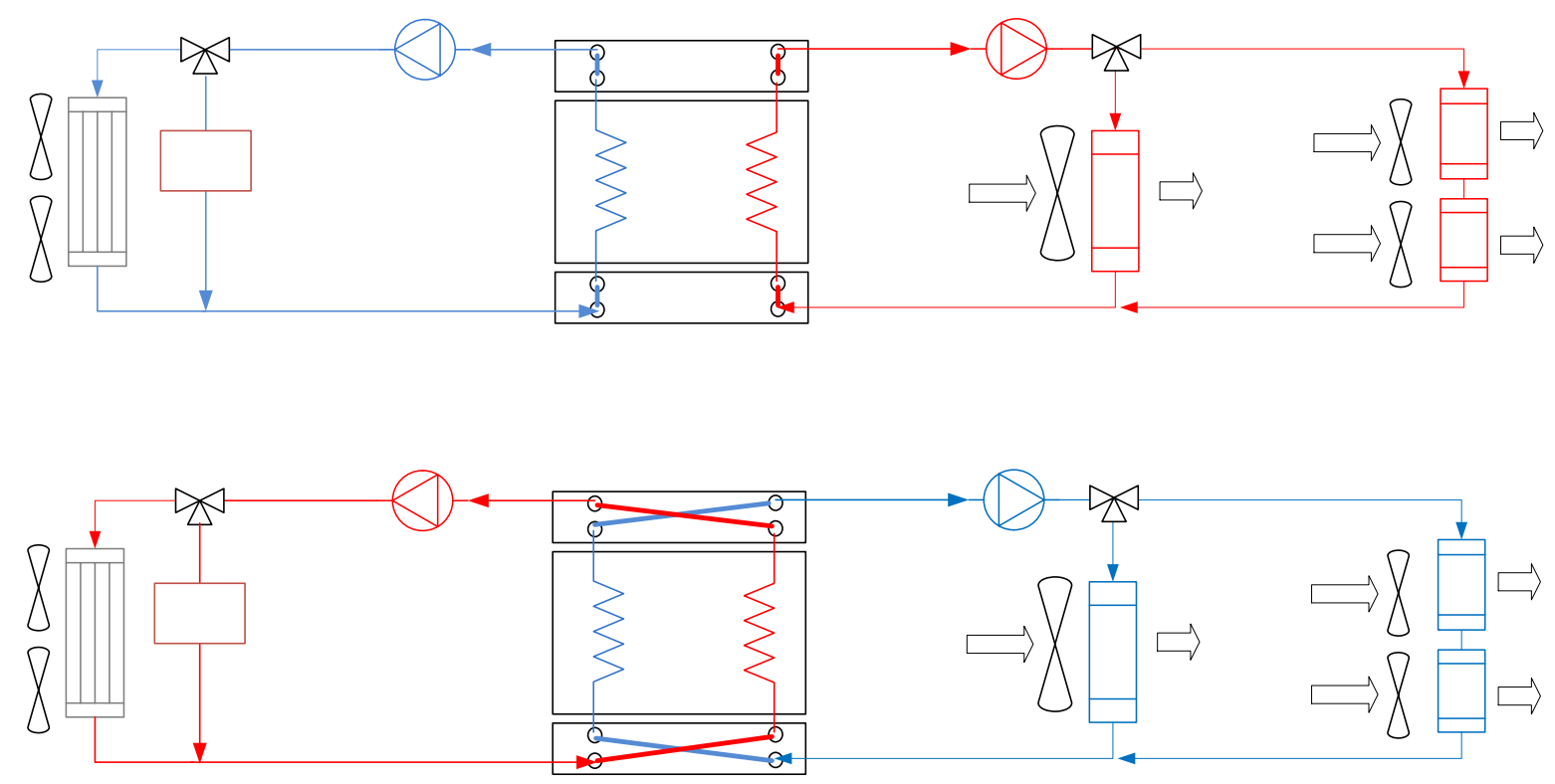

Fig. 1. Integrated air-conditioning system layout for an electric minibus. Above: heating mode. Below: cooling mode.
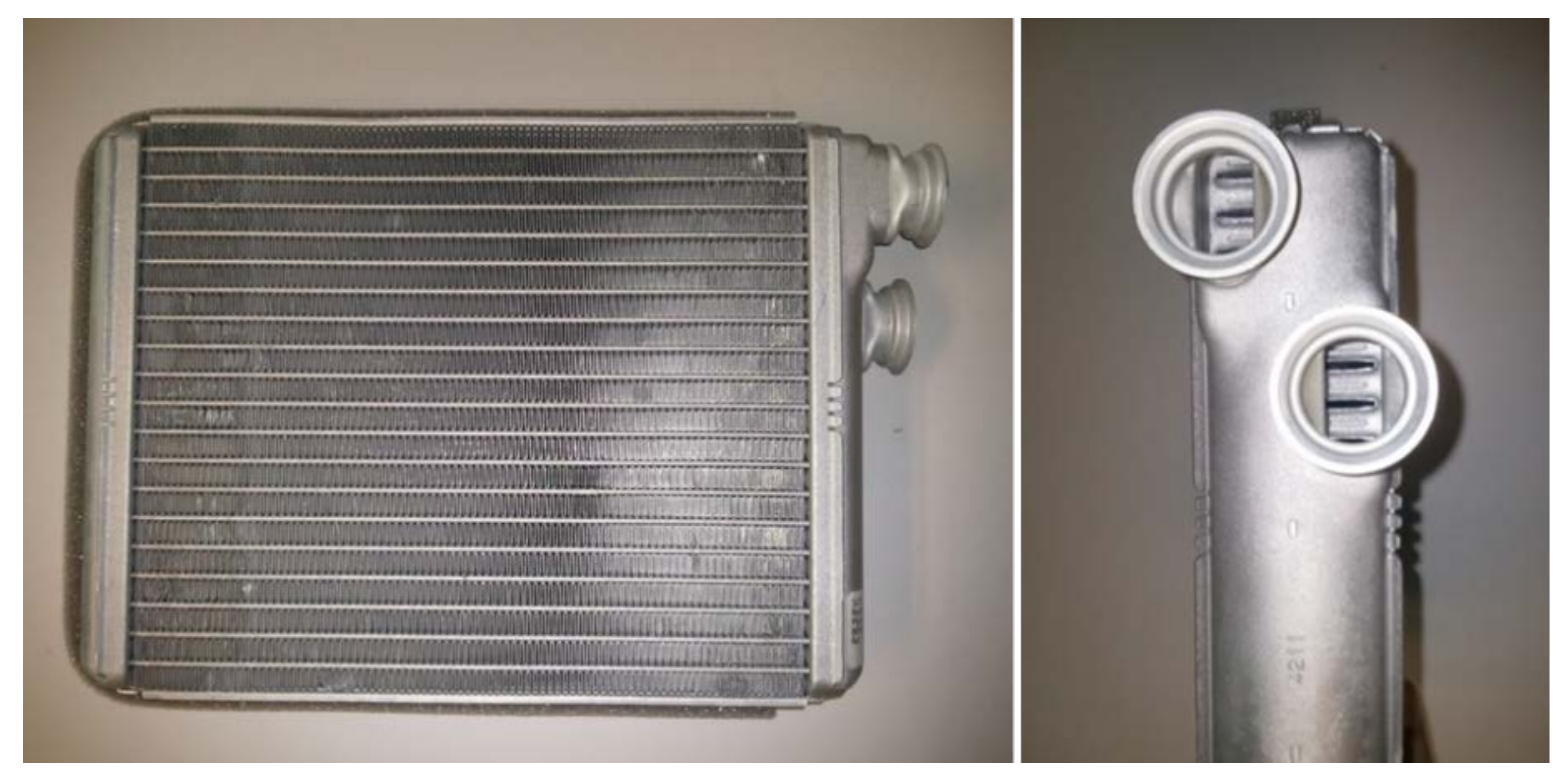

Fig. 2. Photograph of the A51-KS423 compact heat exchanger by MAHLE Behr. 


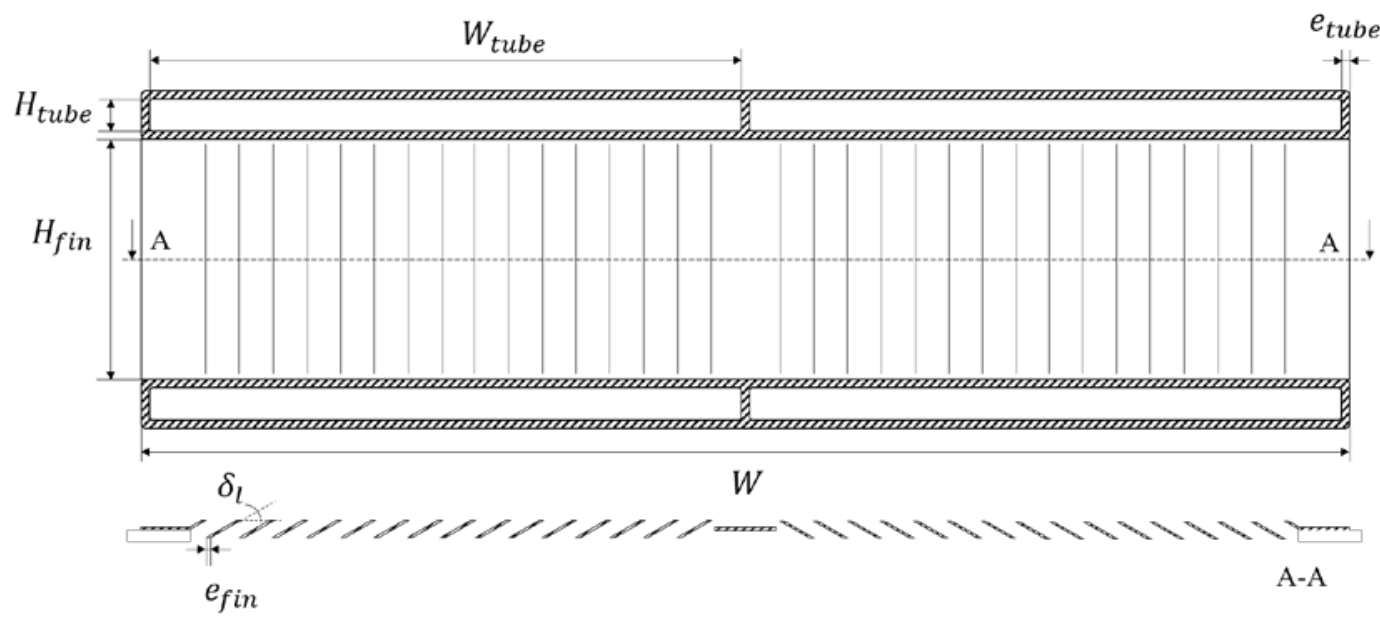

Fig. 3. Geometry of the A51-KS423 compact heat exchanger.

Table 1. Dimensions of the A51-KS423 compact heat exchanger.

\begin{tabular}{|c|c|c|c|c|c|}
\hline Parameter & Value & Parameter & Value & Parameter & Value \\
\hline Number of tubes & 19 & $\mathrm{~L}_{\text {tube }}[\mathrm{mm}]$ & 180.0 & $\mathrm{H}_{\text {fin }}[\mathrm{mm}]$ & 5.94 \\
\hline Passes per tube & 2 & $\mathrm{~W}_{\text {tube }}[\mathrm{mm}]$ & 15.0 & $\mathrm{e}_{\text {fin }}[\mathrm{mm}]$ & 0.10 \\
\hline Core length $(\mathrm{L})[\mathrm{mm}]$ & 180.0 & $\mathrm{H}_{\text {tube }}[\mathrm{mm}]$ & 1.20 & $\delta_{1}[\mathrm{deg}]$ & 30 \\
\hline Core height $(\mathrm{H})[\mathrm{mm}]$ & 151.94 & $\mathrm{e}_{\text {tube }}[\mathrm{mm}]$ & 0.20 & Fin pitch $\left[\mathrm{m}^{-1}\right]$ & 1081 \\
\hline Core width $(\mathrm{W})[\mathrm{mm}]$ & 32.20 & $\mathrm{~d}_{\mathrm{h}, \mathrm{w}}[\mathrm{mm}]$ & 2.22 & $\mathrm{~d}_{\mathrm{h}, \text { air }}[\mathrm{mm}]$ & 1.51 \\
\hline
\end{tabular}

The thermal behaviour of a HEX depends on its geometrical characteristics and on the conditions of both flows. An experimental campaign was carried out by MAHLE with the purpose of characterising the thermal performance of this HEX for its novel use in air-conditioning applications, for both heating and cooling of a vehicle cabin. In order to obtain on-board performance data, the HEX was mounted inside one of the HVAC units of the minibus, which basically consists of a short wind tunnel and a variable speed centrifugal blower. This experimental setup was placed inside a climatic chamber in order to control the inlet air temperature and humidity (Fig. 4).

A scheme of the test setup is shown in Fig. 5. The inlet air temperature and relative humidity were controlled respectively with a $\mathrm{T}$-type thermocouple ( $\pm 0.5 \mathrm{~K}$ uncertainty) and a humidity sensor $( \pm 3 \%$ in the range tested). The air flow rate is provided by a centrifugal blower model SPAL A42-32D, which is the standard component of the HVAC unit and was previously characterized with an accuracy of $\pm 2 \%$. In the present setup, the air flow rate is controlled by means of the power input to the motor of the blower. The outlet air temperature was measured with a grid of $16 \mathrm{~T}$-type thermocouples with an uncertainty of $\pm 0.5 \mathrm{~K}$ placed on the HEX. Additionally, the air temperature at the outlet of the HVAC unit was measured with 8 T-type thermocouples placed along the outlet vent. The mass of condensate was registered by means of a scale $( \pm 0.1 \mathrm{~g})$.

In the coolant side, a solution of $50 \%$ in volume of ethylene glycol in water typical for automotive applications was employed. The experimental facility allowed for controlling the flow rate and inlet temperature of the coolant, which were respectively measured with a Coriolis flow meter (uncertainty $\pm 0.2 \%$ of rate) and 2 T-type thermocouples. The outlet temperature of the coolant was recorded as well by means of $2 \mathrm{~T}$-type thermocouples. 

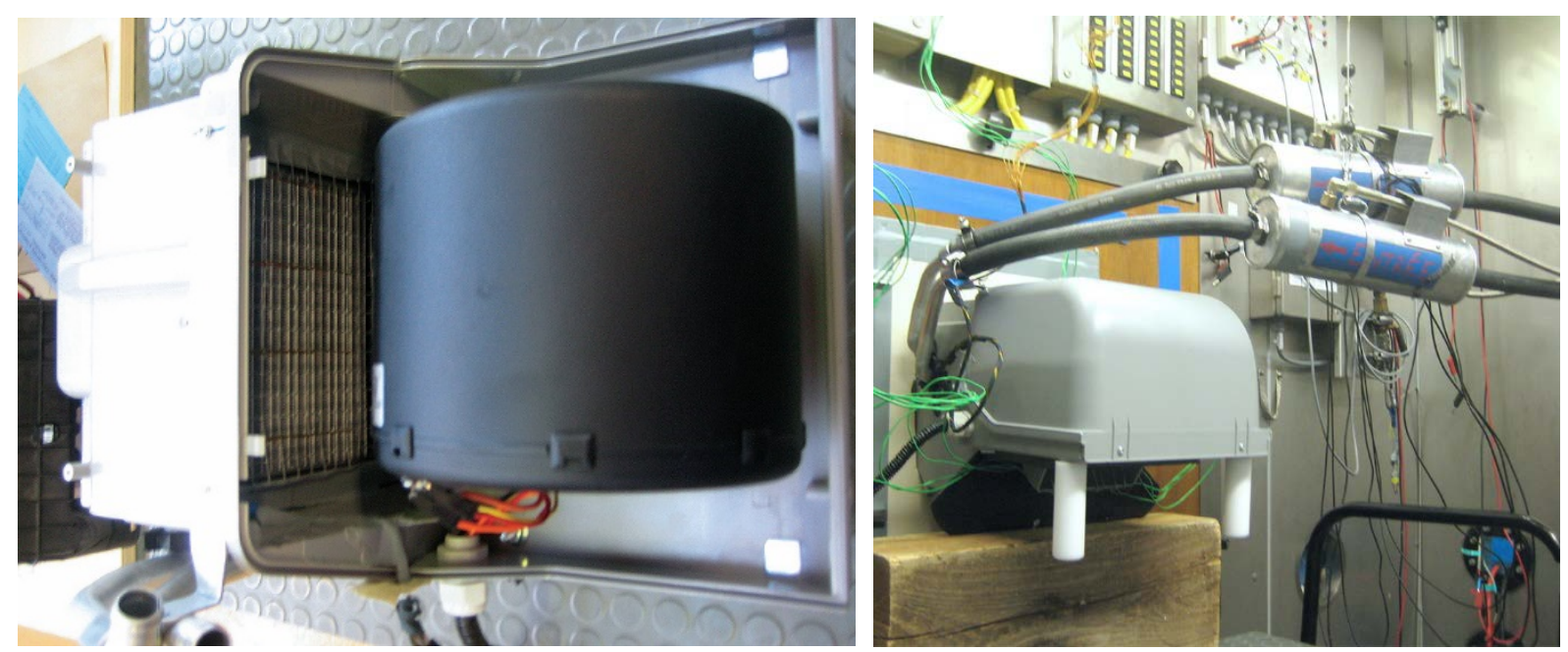

Fig. 4. Experimental setup: HEX inside the HVAC unit (left) and HVAC unit on the test bench (right).

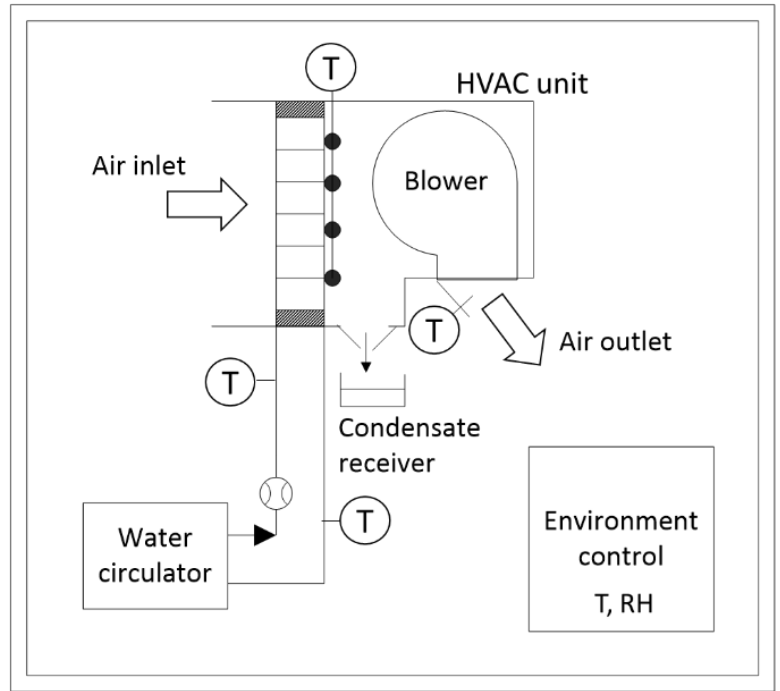

Fig. 5. Scheme of the experimental setup.

The HEX was tested under a wide range of temperatures and flow rates which are representative of the working conditions of an AC system (Table 2). In total 279 operation points were measured, 180 in heating mode and 99 in cooling mode. In the cooling mode tests each point was repeated four times.

Table 2. AC operation points tested by MAHLE.

\begin{tabular}{|c|c|c|c|c|}
\hline Mode & Air inlet T $\left[{ }^{\circ} \mathrm{C}\right] / \mathrm{RH}[\%]$ & Coolant inlet $\mathrm{T}\left[{ }^{\circ} \mathrm{C}\right]$ & Air flow rate $\left[\mathrm{m}^{3} \mathrm{~h}^{-1}\right]$ & Coolant flow rate $\left[\mathrm{m}^{3} \mathrm{~h}^{-1}\right]$ \\
\hline Heating & $0 / 70-10 / 60-20 / 50$ & $30-35-40-50$ & $\begin{array}{c}100-200-250- \\
300-400\end{array}$ & $0.3-0.6-0.9$ \\
\hline Cooling & $20 / 40^{1}-25 / 50-30 / 60$ & $5-10-15$ & $\begin{array}{c}150-200-250- \\
300\end{array}$ & $0.3-0.6-0.9$ \\
\hline
\end{tabular}

${ }^{1} 20^{\circ} \mathrm{C} / 40 \%$ conditions were tested under air flow rates of 100,200 and $300 \mathrm{~m}^{3} \mathrm{~h}^{-1}$

\section{MODEL}

The results of the experimental campaign have been used to find a correlation for the global heat transfer coefficient multiplied by the heat transfer surface (UA) of the studied HEX. For system design purposes, a model of a HEX based on the UA is more convenient than one based on the effectiveness, since the former allows for scaling up and down the HEX and therefore finding its optimum size for the studied application. Besides, employing a correlation for the UA instead of the experimental dot map improves the interpolation and 
extrapolation of the values during the simulations. The methodology explained in this work to fit a correlation for the UA is general and can be applied to other HEX geometries provided that an experimental data set is available.

The UA can be found with the effectiveness-NTU method. The effectiveness $(\varepsilon)$ of the HEX is calculated from the experimental tests by applying its definition for sensible (Eq. 1) or latent (Eq. 2) heat transfer processes (Braun et al. 1989). The thermophysical properties are calculated as function of the mean temperature between the inlet and the outlet of the HEX.

$$
\begin{gathered}
\varepsilon_{d r y, a i r}=\frac{Q}{m_{\text {air }} c_{p, a i r}\left(T_{a i r, i n}-T_{w, i n}\right)} \\
\varepsilon_{\text {wet,air }}=\frac{Q}{m_{\text {air }}\left(i_{\text {air }, \text { in }}-i_{\text {sat }, w, i n}\right)}
\end{gathered}
$$

The value of the heat transfer rate (Q) computed in the coolant side (Eq. 3) has been employed to calculate the effectiveness as in Jokar et al. (2010). Measuring the flow rate and the temperature in the air side is more difficult than in the water side. As observed later, when the air flow rate is low there is a significant dispersion in the results. On the contrary, the measurements in the water side are much more accurate. Regarding the thermal losses, in the present setup the HEX is separated from the walls of the test duct by an insulating foam so it can be assumed that all the heat losses, including the losses from the headers, go to the air inside the duct.

$$
Q=\dot{m}_{w} c_{p, w}\left(T_{w, \text { out }}-T_{w, \text { in }}\right)
$$

The $\varepsilon$ can be written as a function of the NTU, which in turn depends on the UA. The relationship between $\varepsilon$ and NTU depends on the geometry of the HEX. A specific $\varepsilon$-NTU expression for an unmixed cross-flow unit with $n_{\text {pass }}$ passes per tube ( $n_{\text {pass }}=2$ in this case) has been applied (Eqs. 4-7) (Hewitt, 1998). Compared to the commonly employed $\varepsilon$-NTU relationship for an infinite number of tube rows in ESDU (1991), the present expression fits better the experiments and does not have any limitation on the heat capacity of the fluid flows.

$$
\begin{gathered}
\varepsilon=\frac{1}{R}\left(1-\left(\frac{K}{2}+\left(1-\frac{K}{2}\right) e^{2 K R}\right)^{-1}\right) \\
K=1-\exp \left(-\frac{N T U_{\text {air }}}{n_{\text {pass }}}\right) \\
N T U_{\text {air }}=\frac{U A_{\text {air }}}{c_{\text {air }}^{*} m_{\text {air }}} \\
R=\frac{c_{\text {air }}^{*} m_{\text {air }}}{c_{p, w} m_{w}}
\end{gathered}
$$

Where $c_{\text {air }} *$ equals the specific capacity of air $\left(c_{\mathrm{p} \text {,air }}\right)$ if the HEX is dry (sensible process) and $c_{\mathrm{sat}}(\mathrm{Eq} .8)$ if it is wet (latent process) (Braun et al. 1989).

$$
c_{\text {sat }}=\frac{i_{\text {sat }, \text {,in }}-i_{\text {sat }, w, \text { out }}}{T_{w, \text { in }}-T_{w, \text { out }}}
$$

Convection is the dominant heat transfer mode in a heat exchanger (Wang, 1999), hence the UA can be expressed by Eq. (9). 


$$
U A=\frac{1}{\frac{1}{h_{w} A_{w}}+\frac{1}{h_{\text {air }}\left(A_{\text {wall }}+\eta_{\text {fin }} A_{\text {fin }}\right)}}
$$

The HEX surfaces and the fin efficiency $\left(\eta_{\text {fin }}\right)$ are characteristic and constant for a given HEX.

The convection coefficient (h) (Eq. 10) is a function of the Nusselt number (Nu), the fluid conductivity (k) and a characteristic length, in this case the hydraulic diameter $\left(\mathrm{d}_{\mathrm{h}}\right)$, which is a constant geometrical parameter for a given HEX. The Nu (Eq. 11) can be generally expressed as a function of the Prandtl (Pr) and Reynolds (Re) numbers, where $\mathrm{K}, \mathrm{n}$ and $\mathrm{m}$ depend on the flow conditions.

$$
\begin{gathered}
h=\frac{N u k}{d_{h}} \\
N u=K \operatorname{Re}^{n} \operatorname{Pr}^{m}
\end{gathered}
$$

The Pr (Eq. 12) and the Re (Eq. 13) depend on the thermophysical properties of the fluids, which in turn depend on the temperature. In the tests carried out, the variation of the properties due to the temperature difference is assumed to be negligible compared to the effect of the variation of the test conditions. Consequently, the $\mathrm{Pr}$ remains constant and the Re depends only on the fluid mass flow rate, given that the hydraulic diameter $\left(\mathrm{d}_{\mathrm{h}}\right)$ and the cross-sectional surface $\left(\mathrm{A}_{c}\right)$ of the ducts are constant geometrical parameters.

$$
\begin{gathered}
\operatorname{Pr}=\frac{c_{p} \mu}{k} \\
\operatorname{Re}=\frac{m d_{h}}{\mu A_{c}}
\end{gathered}
$$

Therefore, Eq. (9) can be rewritten as Eq. (14), where $K_{1}, K_{2}, n_{1}$ and $n_{2}$ are unknown constants to be fitted.

$$
U A=\frac{1}{\frac{1}{K_{1} m_{w}^{n_{1}}}+\frac{1}{K_{2} m_{\text {air }}^{n_{2}}}}
$$

The exponents $n_{1}$ and $n_{2}$ in Eq. (14) have been found in literature considering the characteristics of the coolant and air flows respectively through the measured HEX.

In the coolant side, the Re in the tests ranges between 115 and 688 so the flow regime is laminar. It is assumed that the mean Nusselt number for hydrodynamically developed laminar flow in flat tubes can be approached by the expression for parallel plates, Eqs. (15-17) (VDI, 2010).

$$
\begin{gathered}
N u_{m}=\left(N u_{1}^{3}+N u_{2}^{3}\right)^{1 / 3} \\
N u_{1}=7.541 \\
N u_{2}=1.841^{\operatorname{RePr} d_{h} / L}
\end{gathered}
$$

Under the conditions measured and due to the geometry of the HEX the value of $\mathrm{Nu}_{\mathrm{m}}$ approaches $\mathrm{Nu}_{2}$, so the rest of the terms in Eq. (15) can be neglected. $n_{1}$ refers to the exponent of the Re in the coolant side, which can be inferred directly from these expressions.

Similarly, $\mathrm{n}_{2}$ is the exponent of the Re in the air side. Several correlations for plate-fin surfaces with louvered fins have been tried to find the value of $n_{2}$ for the tested air flow range. The best results were obtained with the correlation in Webb and Kim (2005). 
The constants $K_{1}$ and $K_{2}$ in Eq. (14) have been calculated in order to minimize the sum of the root mean squared error (RMSE) of the heat transfer rate. If the purpose is to predict the HEX performance, fitting the heat transfer rate provides greater accuracy than fitting the UA values.

$\mathrm{K}_{1}$ refers to the heat transfer conditions in the coolant side, so its value should remain the same regardless the type of process in the air side (sensible or latent). However, in the air side the energy transfer rate during a latent process increases significantly compared to that of a sensible process. Therefore, $K_{2}$ is expected to be larger if the HEX is wet. Two values of $K_{2}$ have been fitted: one to the cases in which the HEX surface in the air side is mainly dry $\left(\mathrm{K}_{2, \text { dry }}\right)$ and the other to the points in which it is mainly wet $\left(\mathrm{K}_{2 \text {,wet }}\right)$. In order to decide the prevailing working condition, the OD approach by Braun et al (1989) for counterflow cooling coils has been followed to model the HEX. This method requires that the UA values are known, therefore the model itself has been employed to find the fitting constants for Eq. (14). A brief description of the methodology is provided in the next paragraphs, for more details on the equations the reader can refer to Braun et al (1989).

First, the HEX is supposed to be all dry, this is, the air is not dehumidified at any point of the HEX so there is only sensible heat transfer. The $\mathrm{Q}$ and the outlet temperatures of the fluids are calculated by means of the effectiveness method with Eq. (1). Then, the temperature of the coil surface at the outlet of the HEX $\left(T_{\mathrm{s}, \text { out }}\right)$ is calculated. If $\mathrm{T}_{\mathrm{s} \text {,out }}$ is higher than the dew point temperature at the inlet of the HEX $\left(\mathrm{T}_{\text {dew,in }}\right)$, the HEX is all dry as assumed.

On the contrary, if $\mathrm{T}_{\mathrm{s} \text {,out }}$ is lower than $\mathrm{T}_{\text {dew,in }}$ the HEX is at least partially wet, that is, dehumidification occurred at some point. In this case, the HEX is assumed to be all wet, this is, the air is dehumidified at all points in the HEX so both sensible and latent heat transfer take place all along the HEX. The calculations are performed again with the corresponding expressions for latent processes (Eq. 2). Finally, the temperature of the coil surface at the inlet of the HEX $\left(T_{s, i n}\right)$ is calculated. If $T_{s, \text { in }}$ is lower than $T_{\text {dew,in }}$ the HEX is all wet as assumed.

However, if $T_{s, i n}$ is higher than $T_{\text {dew,in }}$ and $T_{s, \text { out }}$ is lower than $T_{\text {dew,in, }}$, the coil is only partially wet. In this case, instead of solving iteratively the wet and dry portions of the HEX, the assumption that provides the largest heat transfer rate is chosen. Note that when heating the air there is not dehumidification, so the heat transfer rate in this working mode is always obtained from the all dry expressions.

Finally, Table 3 summarizes the values obtained for the parameters in Eq. (14).

Table 3. Parameters of UA correlation.

\begin{tabular}{|c|c|}
\hline Constant & Value \\
\hline $\mathrm{K}_{1}$ & 545.28 \\
\hline $\mathrm{n}_{1}$ & 0.33 \\
\hline $\mathrm{K}_{2, \text { dry }}$ & 1810.11 \\
\hline $\mathrm{K}_{2, \text { wet }}$ & 3318.72 \\
\hline $\mathrm{n}_{2}$ & 0.58 \\
\hline
\end{tabular}

\section{RESULTS AND DISCUSSION}

\subsection{Experimental results}

The experimental results were validated by calculating the heat transfer rate $(Q)$ in both sides of the heat exchanger. In the coolant side, Eq. 3 was employed. In the air side, the sensible heat gain from the blower has been included in the corresponding expression (analogue to Eq. 3). The average deviation between the heat transfer rates in both sides is $2.7 \%$ in heating mode and $3.0 \%$ in cooling mode. The largest deviations were generally observed at the working points with low air flow rates, which are more difficult to measure. In fact some of these points at low air flow rates produced inconsistencies in the calculation of their effectiveness $(\varepsilon>1)$, so they were not included in the study. 

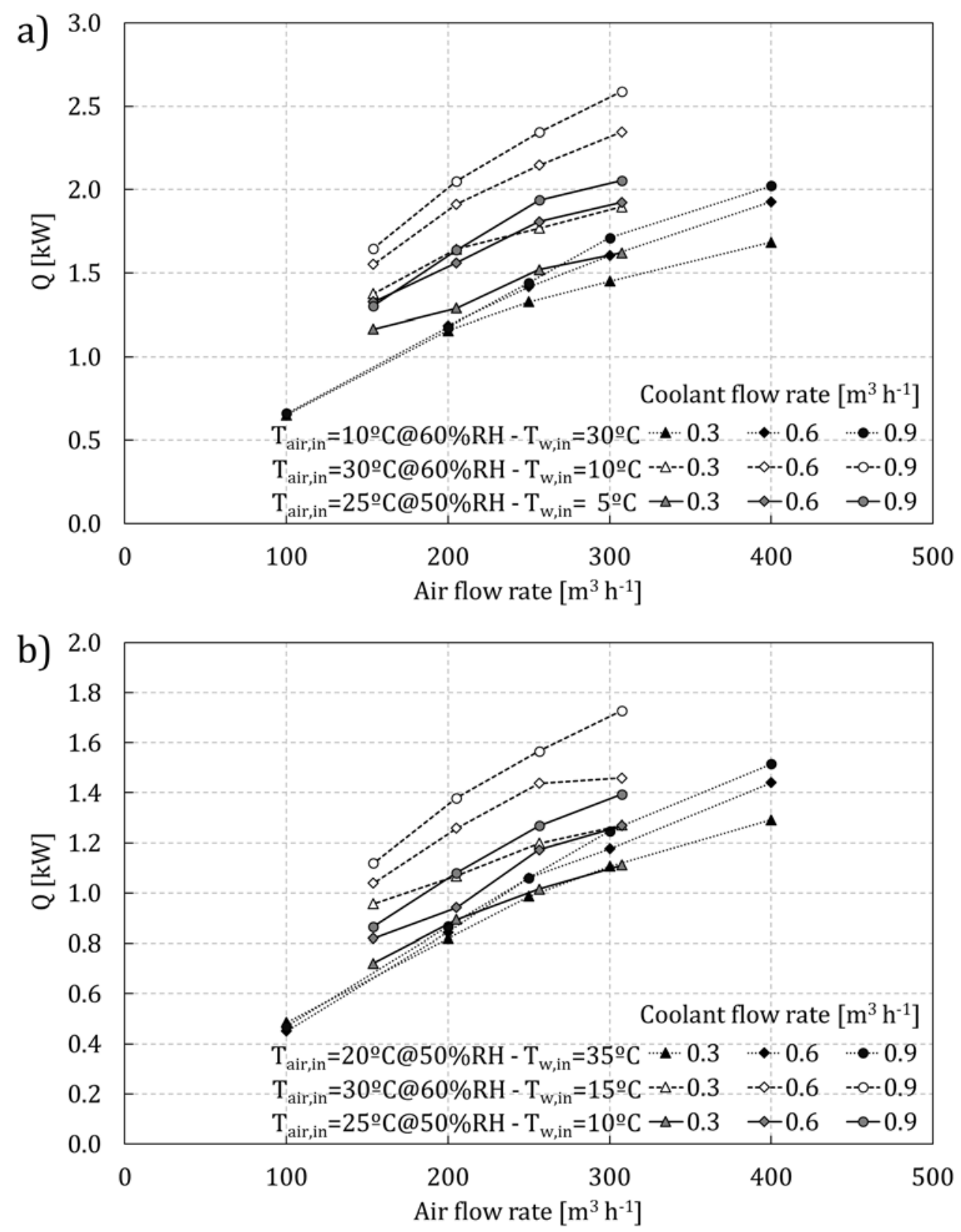

Fig. 6. Experimental Q in the coolant side as a function of the fluid flow rates. a) Cases with inlet temperature differences of $20 \mathrm{~K}$. b) Cases with inlet temperature differences of $15 \mathrm{~K}$.

Fig, 6 shows the heat transfer rate $(Q)$ in the coolant side under some of the conditions in Table 1. As expected, the cases with air dehumidification yield a larger heat transfer rate that the cases with sensible heat transfer only. In the tested parameter space, the latent heat transferred accounts for up to the $50 \%$ of the total heat in the working points with the largest heat transfer potential $\left(\mathrm{T}_{\mathrm{air}, \mathrm{in}}=30^{\circ} \mathrm{C} @ 60 \% \mathrm{RH}\right.$ and $\left.\mathrm{T}_{\mathrm{w}, \mathrm{in}}=5^{\circ} \mathrm{C}\right)$. In Fig. 6, the points that do not follow the general trends are caused by the condensate mass flow rate registered. Fig. 7 shows the sensible heat ratio (SHR) of the air cooling cases represented in Fig. 6. The variations observed in Fig. 6 can be explained by the variations in the SHR, which may have been caused by the exceptional accumulation of the condensate at some point of the test setup. Nevertheless, a relevant result is that in general the tested heater core could efficiently evacuate the condensate. 


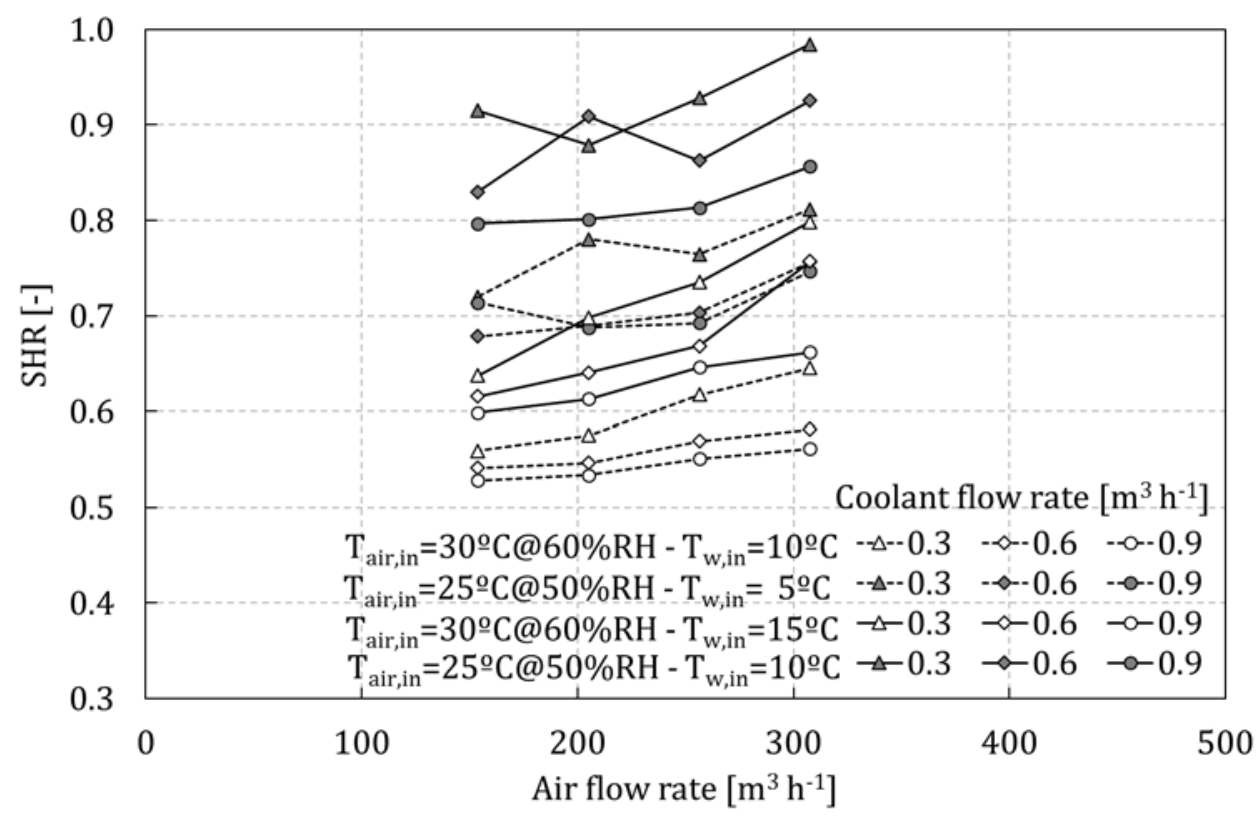

Fig. 7. Experimental sensible heat ratio (SHR) for air cooling cases with inlet temperature differences of $20 \mathrm{~K}$ and $15 \mathrm{~K}$.

\subsection{Model validation results}

Fig. 8 and Fig. 9 compare the experimental values of the heat transfer rate (Q) in the coolant side with the values obtained by means of the correlation. The proposed correlation achieves a good accuracy for all the conditions tested in both cooling and heating modes: the average relative error is $2.4 \%$ and the maximum, $14.0 \%$.

Fig. 8 shows the cases in which the coil was partially wet. Although different values of the condensate mass flow rate were measured, treating each working point as if the HEX surface was either all wet or all dry provides a good accuracy. Compared to fitting a single value for $K_{2}$, differentiating between mainly wet $\left(K_{2 \text {,wet }}\right)$ and mainly dry $\left(\mathrm{K}_{2, \text { dry }}\right)$ conditions reduced the average relative error by 1.2 percentage points and the maximum by 5.1. The largest errors, up to $-12.4 \%$, are produced by the cases in which the latent heat load is low but the working conditions are still closer to all wet. As noted in Braun et al. (1989), in these conditions the heat transfer rate is underpredicted. 


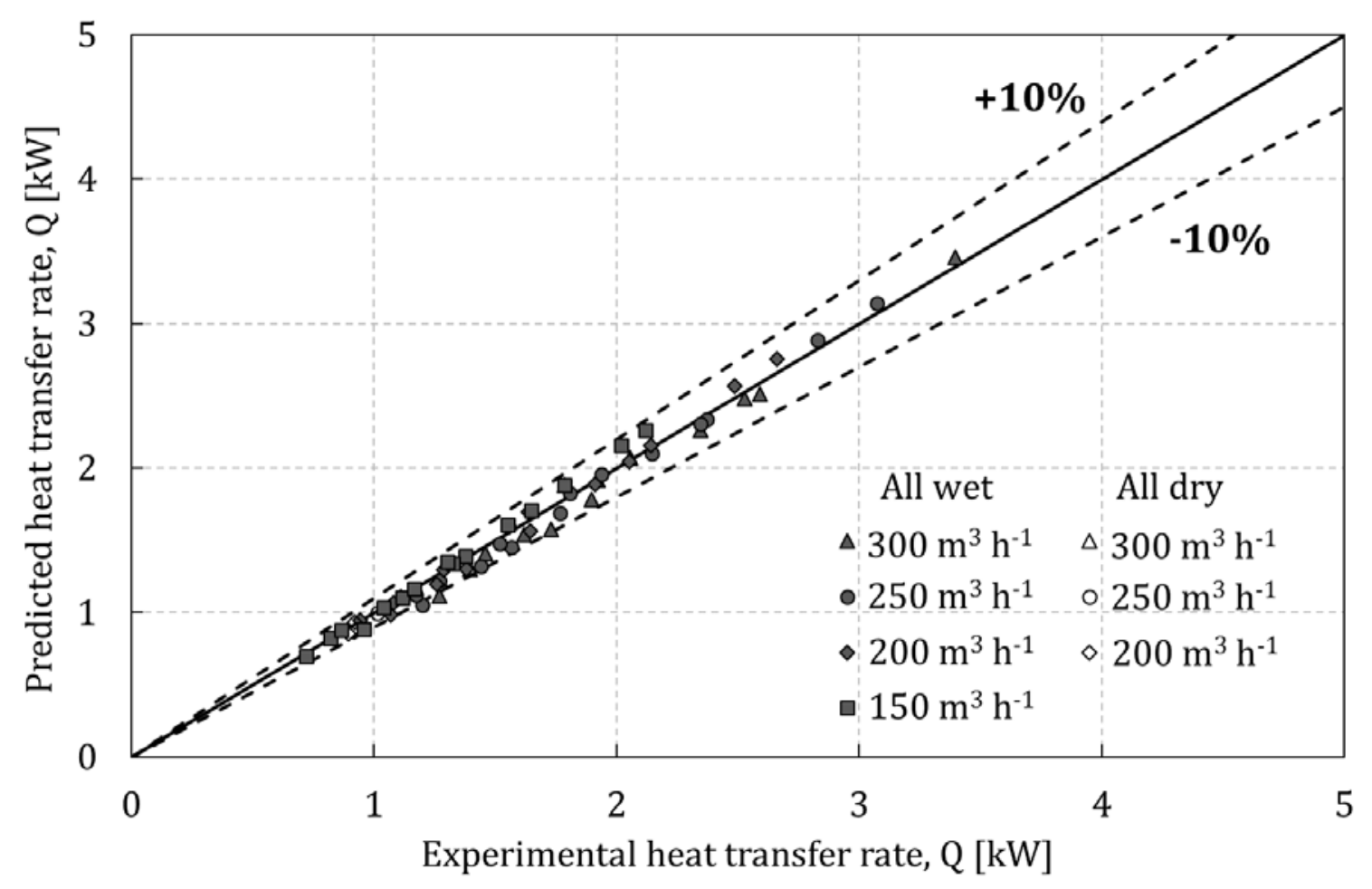

Fig. 8. Experimental and predicted Q as a function of the air flow rate for partially wet working conditions.

Fig. 9 shows the cases in which the HEX was all dry. As expected, a single value of the constants in Eq. (14) fits both air cooling and heating modes. The largest errors, up to 14.0\%, correspond mainly to cases with low air flow rates, which are difficult to measure. As commented before some of these cases produced experimental effectiveness values larger than one, nevertheless the correlation achieved good predictions.

Similarly, Fig. 10 and Fig. 11 compare the UA values obtained from the experimental tests with the values from the fitted correlation. As expected the dispersion and the deviation are larger than the ones observed for the heat transfer rate, but generally the relative error is less than $20 \%$ for both partially wet (Fig. 10) and all dry (Fig. 11) working conditions. 


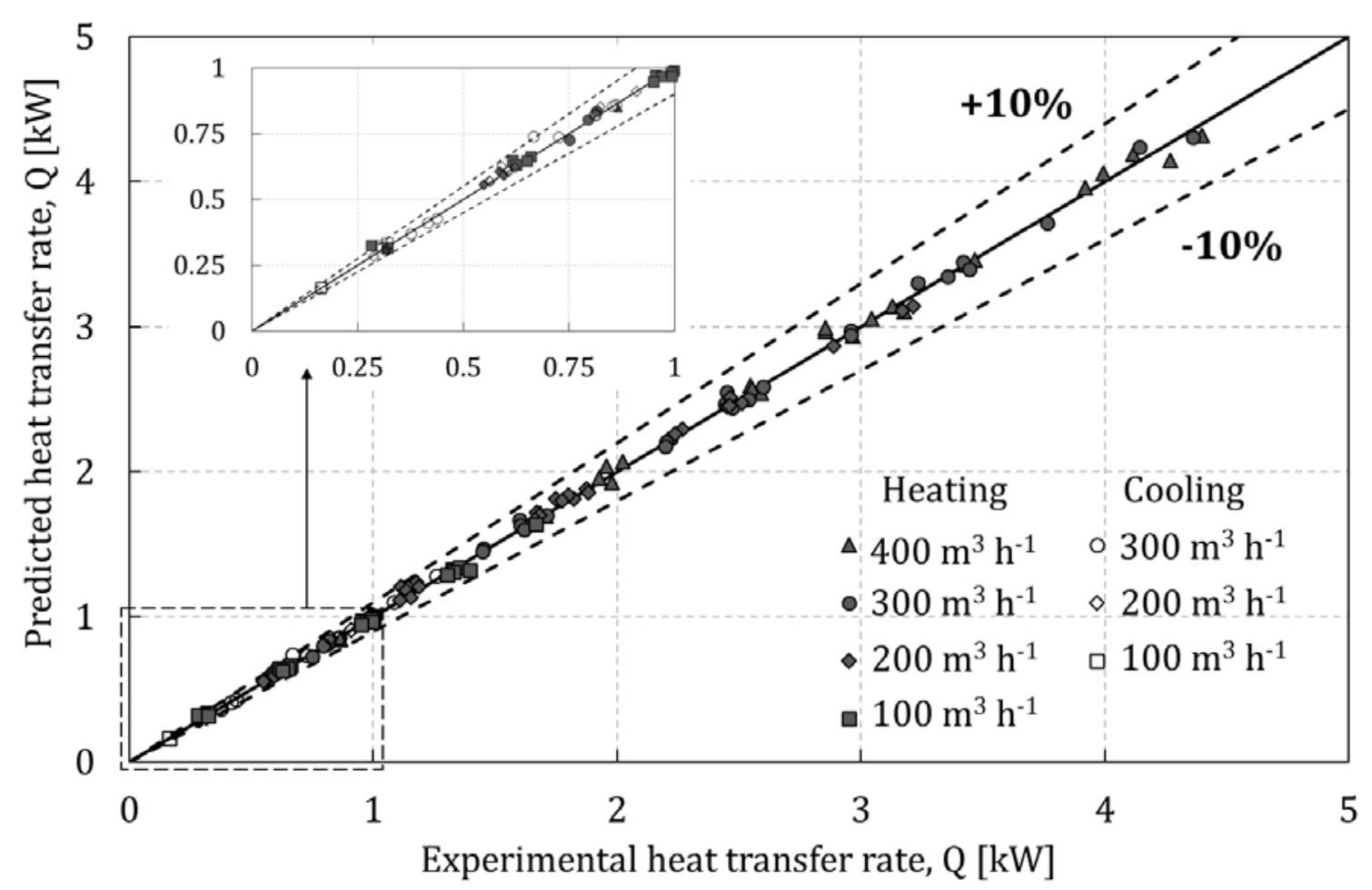

Fig. 9. Experimental and predicted $Q$ as a function of the air flow rate for all dry working conditions. The inset zooms the region where $\mathrm{Q}<1 \mathrm{~kW}$.

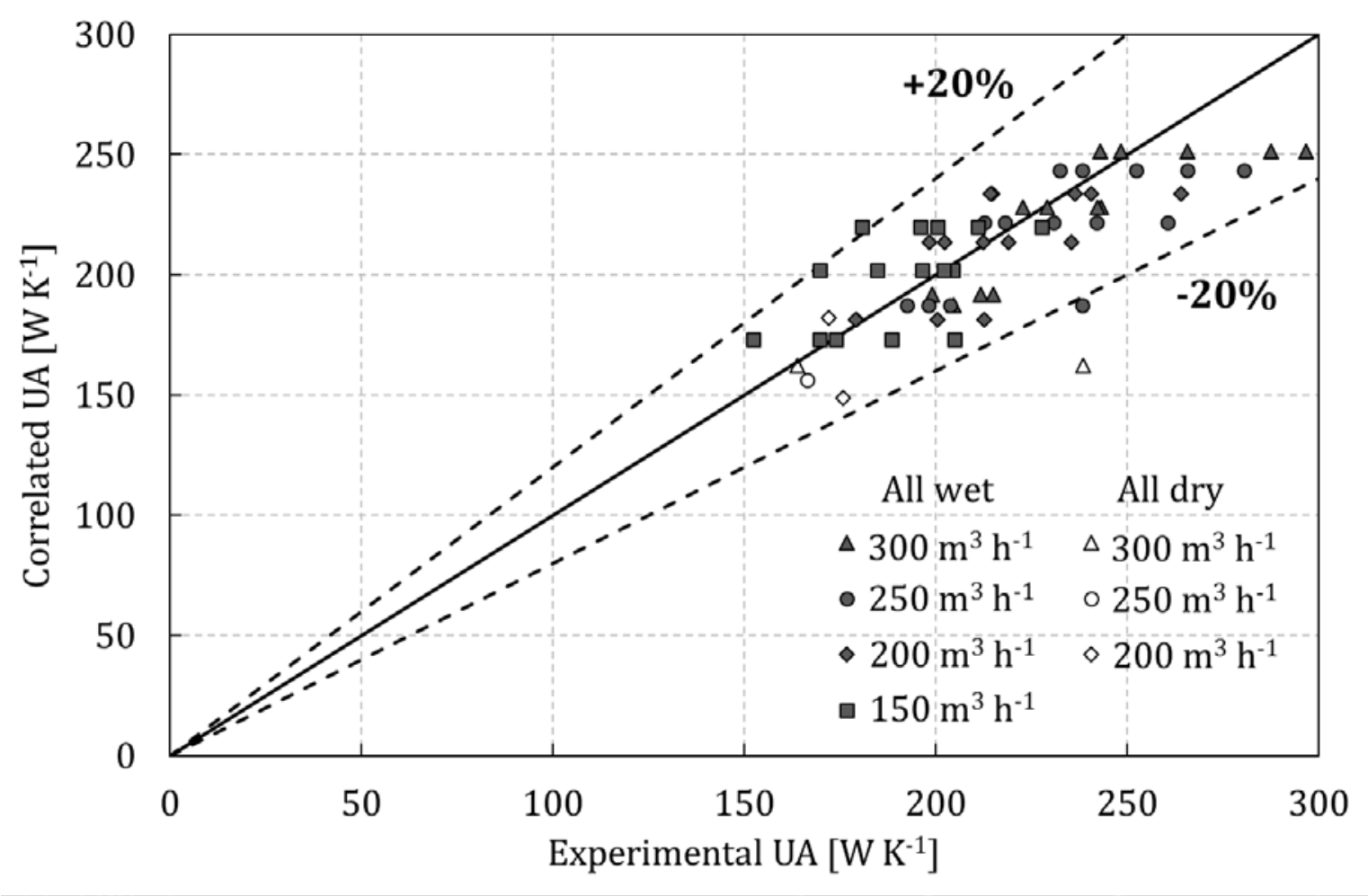

Fig. 10. Experimental and correlated UA as a function of the air flow rate for partially wet working conditions. 


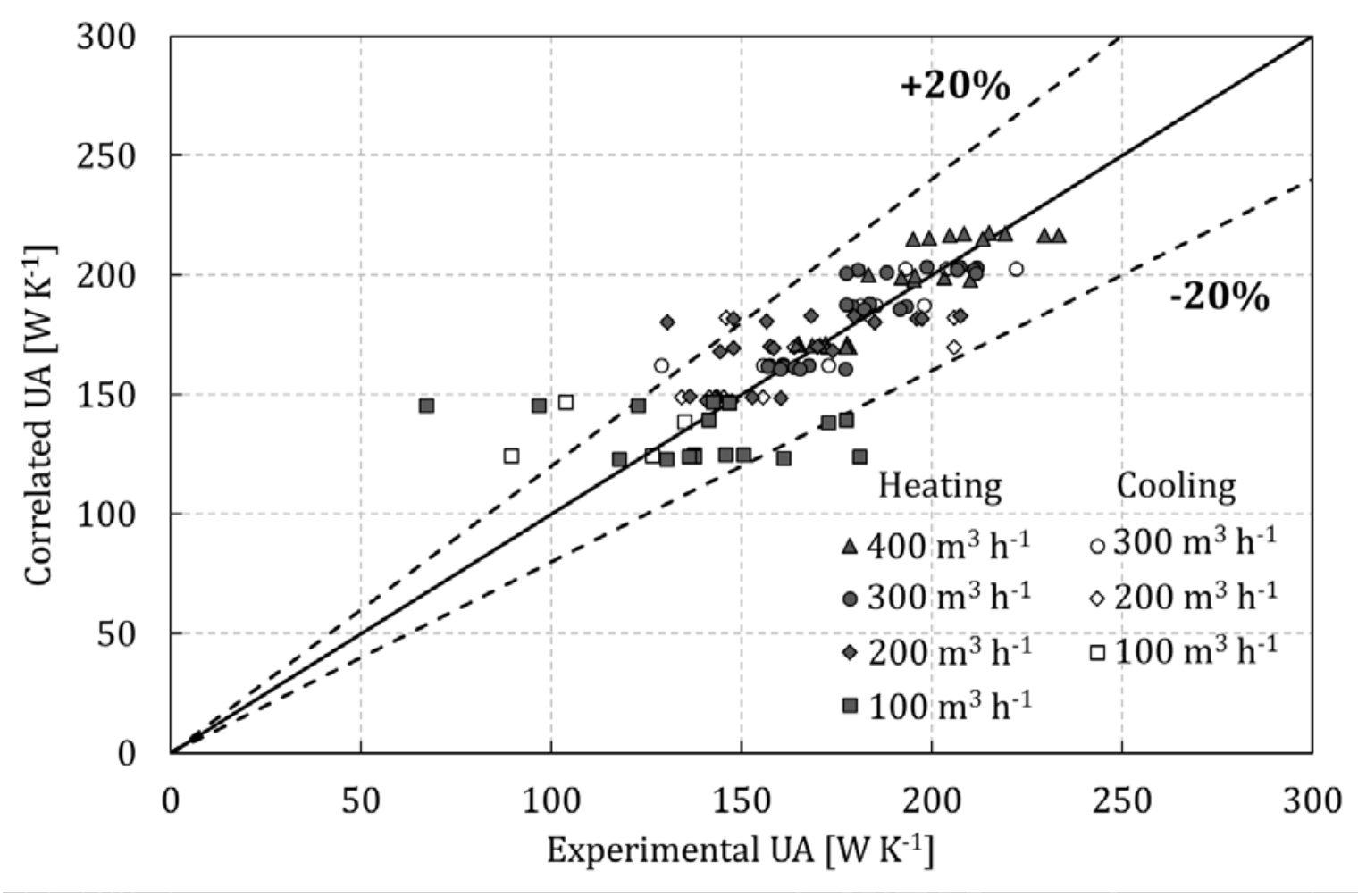

Fig. 11. Experimental and correlated UA as a function of the air flow rate for all dry working conditions.

As commented before, the cases with the lowest flow rates generally yield the largest errors (Fig. 10). For instance, Fig. 12 shows the UA values of two experimental data set with the inlet temperatures fixed. The experimental UA values for an air flow rate of $100 \mathrm{~m}^{3} \mathrm{~h}^{-1}$ do not follow the trend of the points around. The case with a coolant flow rate of $0.9 \mathrm{~m}^{3} \mathrm{~h}^{-1}$ and an air flow rate of $100 \mathrm{~m}^{3} \mathrm{~h}^{-1}$ produced an effectiveness value larger than one and hence the corresponding UA value could not be obtained. However, the fitted correlation prevents the experimental dispersion and predicts a coherent value for the points missed, as suggested by the results in Fig. 9 .

In the context of a model comprising a complete mobile air-conditioning system, the main outputs from the HEX model are the outlet temperatures of the air and the coolant. Fig. 13 is deducted from the results of the heat transfer rate (Fig. 8 and Fig. 9) and compares the experimental temperature variations in the HEX with the predictions of the model in air cooling mode, including partially wet and all dry working conditions. Since the inlet temperatures are inputs to the model, the maximum deviation in the coolant outlet temperature is $0.41 \mathrm{~K}$ and in the air outlet temperature, $1.74 \mathrm{~K}$. These results definitely validate the model and confirm the excellent accuracy of the developed approach. 


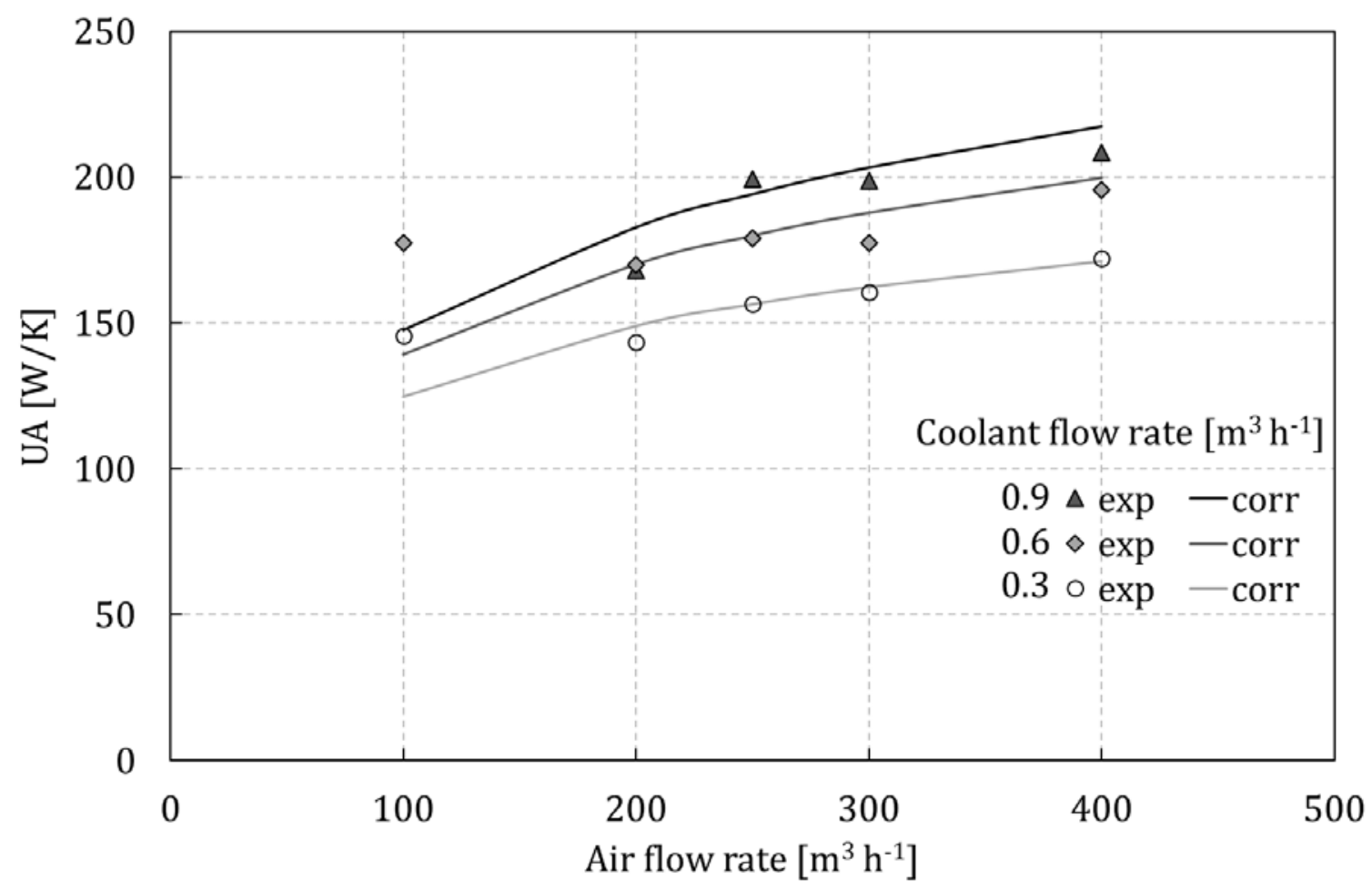

Fig. 12. Experimental (exp) and correlated (corr) UA values as a function of the air and coolant flow rates, for the case $\mathrm{T}_{\mathrm{in}, \mathrm{w}}=40^{\circ} \mathrm{C}$ and $\mathrm{T}_{\mathrm{in}, \mathrm{air}}=0^{\circ} \mathrm{C}$.

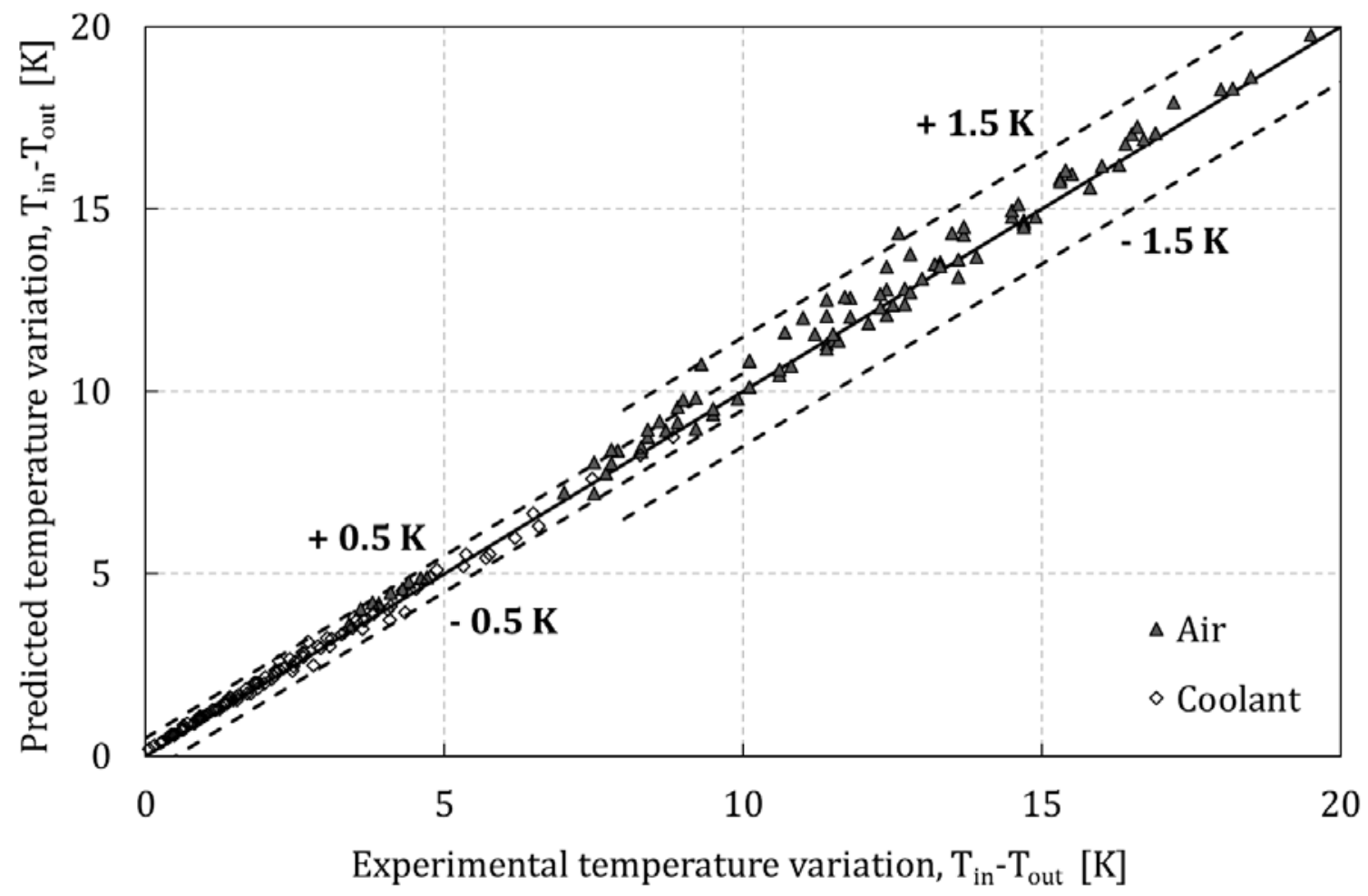

Fig. 13. Experimental and predicted fluid temperature variation in both sides of the HEX for cooling mode. 


\section{CONCLUSIONS}

A compact louvered-fin flat-tube HEX for automotive applications (normally employed as heater core) has been comprehensively tested under both air cooling and heating working conditions for its novel use in the airconditioning of electric vehicles with integrated thermal systems. The experimental campaign consisted of 279 different points, including partially wet and all dry working conditions, in which the outlet temperatures of the fluids (coolant and air) and the condensate mass flow rate were measured. The HEX showed very good performance and moreover was able to efficiently drain the condensate without difficulties under wet conditions, so its design, originally targeted for heater core application, can perfectly work as heating/cooling HEX.

The performance results have been used to fit a semiempirical correlation for the HEX UA value in order to predict the heating/cooling capacity of the studied HEX, nevertheless the methodology explained is general.

The proposed UA correlation, Eq. (14), depends on the fluid mass flow rates and contains only four parameters. Differentiating between mainly wet and mainly dry working conditions by means of the value of the constant for the air side improves substantially the quality of the fitting for the cases with dehumidification. The other three parameters can take a single value for all the tested conditions regardless of the working mode (air cooling or heating) (Table 3).

The UA correlation has been fitted to the experimental heat transfer rate values with the aim of achieving a good prediction of the heat transferred and the outlet temperatures of the fluids. This approach contributed to reduce the experimental dispersion associated to the UA values. The single-node modelling method in Braun et al. (1989) for partially wet working conditions in counterflow cooling coils has been employed to find the values of the fitting parameters, substituting the reported $\varepsilon$-NTU correlation by a specific one for the present cross-flow HEX. The results show high predictive accuracy: the average relative deviation in the predicted heat transfer rate for the cases with dehumidification is $3.5 \%$ and for the all dry cases, $1.9 \%$.

The developed single-node HEX model is useful for its integration in global system models, where reasonable accuracy and minimum computation time are required. For real air-conditioning working conditions, the present model predicts the coolant outlet temperature within $0.4 \mathrm{~K}$ and the air outlet temperature within $1.7 \mathrm{~K}$.

\section{ACKNOWLEDGEMENTS}

This work has been supported by the European Commission under the 7th European Community framework program as part of the ICE project “MagnetoCaloric Refrigeration for Efficient Electric Air-Conditioning”, Grant Agreement no. 265434. B. Torregrosa-Jaime acknowledges the Spanish Education, Culture and Sport Ministry (Ministerio de Educación, Cultura y Deporte) for receiving the Research Fellowship FPU ref. AP2010-2160.

\section{NOMENCLATURE}

A Surface $\left[\mathrm{m}^{2}\right]$

$\mathrm{A}_{\mathrm{C}} \quad$ Cross-sectional surface $\left[\mathrm{m}^{2}\right]$

c $\quad$ Specific heat capacity $\left[\mathrm{J} \mathrm{kg}^{-1} \mathrm{~K}^{-1}\right]$

$\mathrm{d}_{\mathrm{h}} \quad$ Hydraulic diameter [m]

e Thickness [m]

$\mathrm{H} \quad$ Height [m]

$\mathrm{h} \quad$ Convection coefficient [ $\left.\mathrm{W} \mathrm{m}^{-2} \mathrm{~K}^{-1}\right]$

i $\quad$ Specific enthalpy $\left[\mathrm{J} \mathrm{kg}^{-1}\right]$

$\mathrm{k}$ Thermal conductivity [ $\left.\mathrm{W} \mathrm{m} \mathrm{m}^{-1} \mathrm{~K}^{-1}\right]$

L $\quad$ Tube length [m]

$\dot{\mathrm{m}} \quad$ Mass flow rate $\left[\mathrm{kg} \mathrm{s}^{-1}\right]$

$\mathrm{n}_{\text {pass }} \quad$ Number of passes per tube [-]

NTU Number of Transfer Units [-]

$\mathrm{Nu} \quad$ Nusselt number [-]

Pr Prandtl number [-]

Q Heat transfer rate [W]

$\mathrm{R} \quad$ Heat capacity ratio [-]

Re Reynolds number [-]

$\mathrm{T}$ Temperature [K]

$\mathrm{U} \quad$ Global heat transfer coefficient $\left[\mathrm{W} \mathrm{m}^{-2} \mathrm{~K}^{-1}\right]$

W Width [W]

$\begin{array}{ll}\varepsilon & \text { Effectiveness [-] } \\ \mu & \text { Viscosity [Pa s] } \\ \eta & \text { Efficiency [-] } \\ \delta_{1} & \text { Louver angle [deg] }\end{array}$

$\begin{array}{cl}\text { Subscripts } \\ \text { air } & \text { Air side } \\ \text { dew } & \text { Dew point } \\ \text { dry } & \text { Dry conditions } \\ \text { fin } & \text { Fin } \\ \text { in } & \text { Inlet } \\ \text { m } & \text { Mean } \\ \text { out } & \text { Outlet } \\ \text { p } & \text { Constant pressure } \\ \text { s } & \text { Surface conditions } \\ \text { sat } & \text { Saturation } \\ \text { tube } & \text { Tube } \\ \text { w } & \text { Coolant side } \\ \text { wall } & \text { Tube wall } \\ \text { wet } & \text { Wet conditions }\end{array}$




\section{REFERENCES}

Afram, A., and Janabi-Sharifi, F., 2014, Review of Modeling Methods for HVAC Systems, Appl. Therm. Eng., Vol. 67, pp. 507-519.

Bjurling, F., Corberán, J. M., Payá, J., and Torregrosa-Jaime, B., 2014, Control Strategies for the AirConditioning in Electric Vehicles, Proc. VII Congreso Ibérico y V Congreso Iberoamericano de Ciencias y Técnicas del Frío, CYTEF 2014, Tarragona, Spain, Vol. 7, pp. 769-777.

Braun, J. E., Klein, S. A., and Mitchell, J. W., 1989, Effectiveness Models for Cooling Towers and Cooling Coils, ASHRAE Transactions, Vol. 95, pp. 164-174.

ESDU 86018, 1991, Engineering Science Data Unit 86018 with Amendment A, July 1991, ESDU International plc, London, pp. 92-107.

Hewitt, G.F. (Ed.), 1998, Heat Exchanger Design Handbook 1998, Begell House Inc., New York, p. 1.5-3.8. ICE Project FP7, 2014, www.ice-mac-ev.eu.

Jin, G.Y., Cai, W. J., Wang, Y. W., and Yao, Y., 2006, A Simple Dynamic Model of Cooling Coil Unit, Energy Convers. Manage., Vol. 47, pp. 2659-2672.

Jokar, A., Eckels, S. J., and Hosni, M. H., 2010, Single-Phase Flow in Meso-Channel Compact Heat Exchangers for Air Conditioning Applications, Heat Transfer Eng., Vol. 31, pp. 3-16.

Kowsky, C., Wolfe, E., Leitzel, L., and Oddi, F., 2012, Unitary HPAC System, SAE Int. J. Passeng. Cars Mech. Syst., Vol. 5, pp. 1016-1025.

Lee, J. T., Kwon, S. K., Lim, Y. S., Chon, M. S., and Kim, D. S., 2013, Effect of Air-Conditioning on Driving Range of Electric Vehicle for various Driving Modes, SAE Technical Paper 2013-01-0040.

Leighton, D., 2015, Combined Fluid Loop Thermal Management for Electric Drive Vehicle Range Improvement, SAE Int. J. Passeng. Cars - Mech. Syst., Vol. 8, pp. 711-720.

Liang, Y. Y., Liu, C. C., Li, C. Z., and Chen, J. P., 2015, Experimental and Simulation Study on the Air Side Thermal Hydraulic Performance of Automotive Heat Exchangers, App. Therm. Eng., Vol. 87, pp. 305-315.

Oliet, C., Pérez-Segarra, C. D., Danov, S., and Oliva, A., 2007, Numerical Simulation of Dehumidifying Finand-Tube Heat Exchangers: Semi-Analytical Modelling and Experimental Comparison, Int. J. Refrig., Vol. 30, pp. 1266-1277.

Park, Y. G., and Jacobi, A. M., 2009a, Air-Side Heat Transfer and Friction Correlations for Flat-Tube LouverFin Heat Exchangers, J. Heat Transf., Vol. 131, 021801.

Park, Y. G., and Jacobi, A. M., 2009b, The Air-Side Thermal-Hydraulic Performance of Flat-Tube Heat Exchangers with Louvered, Wavy, and Plain Fins Under Dry and Wet Conditions, J. Heat Transf., Vol. 131, 061801.

Qi, Z., 2014, Advances on Air Conditioning and Heat Pump System in Electric Vehicles - A Review, Renew. Sust. Energ. Rev., Vol. 38, pp. 754-764.

Torregrosa-Jaime, B., Payá, J., and Corberán, J.M., 2013a, Design of Efficient Air-Conditioning Systems for Electric Vehicles, SAE Int. J. Alt. Power., Vol. 2, pp. 291-303.

Torregrosa-Jaime, B., Payá, J., Corberán, J.M., Malvicino, C.A., and Di Sciullo, F., 2013b, ICE Project:

Mobile Air-Conditioning System Based on Magnetic Refrigeration, SAE Technical Papers 2013-01-0238.

Vaisi, A., Esmaeilpour, M., and Taherian, H., 2011, Experimental Investigation of Geometry Effects on the Performance of a Compact Louvered Heat Exchanger, App. Therm. Eng, Vol. 31, pp. 3337-3346.

VDI, 2010, VDI Heat Atlas, 2nd ed., Springer, Düsseldorf, pp. 707-708.

Wang, C. C., 1999, On the Airside Performance of Fin-and-Tube Heat Exchangers, in Heat Transfer Enhancement of Heat Exchangers, eds. S. Kakaç, A. E. Bergles, F. Mayinger and H. Yüncü, Springer, Netherlands, Vol. 355, pp. 141-162.

Webb, R. L., and Kim, N. H., 2005, Principles of Enhanced Heat Transfer, 2nd ed., Taylor \& Francis, New York, pp. 101.

Xu, B., Zhang, C., Wang, Y., Chen, J., Xu, K., Li, F., and Wang, N., 2015, Experimental Investigation of the Performance of Microchannel Heat Exchangers with a New Type of Fin Under Wet and Frosting Conditions, App. Therm. Eng, Vol. 89, pp. 444-458.

Zhou, P., 2008, Electric Vehicle Thermal Management System, U. S. Patent 2008/0251235 A1, assigned to Tesla Motors, Inc. 